\title{
Development of Farm simulation application, an example for gamification in higher education
}

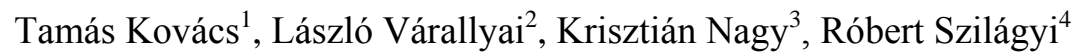

\section{N F O}

Received 26 Feb 2017

Accepted 7 Jun. 2017

Available on-line 14 Aug 2017

Responsible Editor: M. Herdon

\section{Keywords:}

Development, farm simulation, gamification

\begin{abstract}
$\underline{\text { A B S T R A C T }}$
Online applications and games are related to continuous innovation, technical and technological advances in last decades. Our digital society based on technological advancements, because changing consumer requirements need quick and new solutions in the field of technology. We created an online farm simulation application which is called Crownking. The program is based on PHP language and has a MySQL database. The game has great similarity to real life because it has factors which can directly affect the growth of the crops, such as weather, soil quality, soil maintain and the player's profession. Our main goal is help students in learning with the help of gamification, and, moreover to introduce the agriculture to the young generation, and give some spirit about farmer's life.
\end{abstract}

\section{Introduction}

Online gaming has an important role in everyday life, that's why there is a growing demand for online solutions on the part of both the users and the consumers. The penetration rate of the internet is higher than the television and mobile phone penetration rate. We can use it for news and information collection, gaming, entertainment, messages, buying and as also to learn how to highlight the most important ones (Bognár, 2009). The online applications and games are related to continuous innovation, technical and technological advances in last decades. Our digital society based on technological advancements, because the changing consumer requirements need quick and new solutions in the field of technology (Ráthonyi et al., 2016). It is well known that information value and quantity is changed a lot over the recent decades. Actually our society is called information society. The idea of information society was noted first in 1960 in Japan (Z. Karvalics, 2007). During the first note of the idea of the information society has several other political dimensions, so its significance has increased, and actually that is why the concept covers society highly related to the quality and quantity of information (Botos et al., 2015). The information requirements related to the data-centered society. These data can be stored in database and proper databases lead to data warehouse. With the help of data-transformation, and data mining we are able to get great visualized and highly informative information. The gamification is an innovative and impressive methodology to motivate students and help their learning process and comprehends. Although gamification presents good results in education, effective use of this method is still a neglected area of research (Martí-Parreño et al., 2016). So the methods of online learning are more and more popular, and therefore play an increasingly

\author{
${ }^{1}$ Tamás Kovács \\ University of Debrecen \\ tkovacs20@gmail.com \\ ${ }^{2}$ László Várallyai \\ University of Debrecen \\ varallyai.laszlo@econ.unideb.hu \\ ${ }^{3}$ Krisztián Nagy \\ Galway-Mayo Institute of Technology (GMIT) \\ mxsxs2@gmail.com \\ ${ }^{4}$ Róbert Szilágyi \\ University of Debrecen \\ szilagyi.robert@econ.unideb.hu
}

Tamás Kovács, László Várallyai Krisztián Nagy, Róbert Szilágyi: Development of Farm simulation application, an example for gamification in higher education 
important role in nowadaystoday. Thus we have created an online farm simulation application, Crownking. The program is based on PHP language and has a MySQL database. Our main purpose is to help students in learning with the help of gamification, and moreover to introduce the agriculture to the young generation, and give some spirit about farmer's life.

\section{Gamification}

One definition of gamification is "The use of game design elements and game mechanics in nongame contexts in order to engage people and solve problems" (Su and Cheng, 2015). In the other way (Clark et al., 2011) suggest an increasing interest in the use of gamification in education to improve students' engagement and learning outcomes. McGonigal, 2011 has stated that the game elements and the nature of games themselves are motivating. Therefore, applying the idea of game to the education may increase students' motivation to learn (Hanus \& Fox, 2015).

We can talk about a less widespread phenomenon in Hungary and it's important to clarify the meaning of the word itself. The gamification is made up of two words: the Game, like playing and Fication like to change into something or do something. Some companies use it to be a kind of gamebased design appearance or advertise themselves, so they use it as a marketing tool. It is more and more fashionable and it has become increasingly common method in recent years, but has also appeared in education after the millennium. It allows the teacher to teach even through a virtual world, or examining or share learning materials with their students. It is a great opportunity to provide a common way of learning sessions in small groups through the development of individual problemsolving skills, depending on their direction of development (Pataki, 2016). The competition, progress and success of the experience can be really motivating factors even in higher education. It is important that the players themselves can form opinions about issues raised during the play and receive problem solving help if necessary (Martí-Parreño et al., 2016). The concept itself is not yet proven, it can only be delimited depending on the application. So more of them call the design concept and gameplay in this way, which aims at the students' motivation and help them to achieve their goals.

It is interesting that there is a separate section within the gamification of "science", which is aimed at psychology of the game, learn so many things from simple game tasks. The gamification allows us to measure including the player's motivation, personality of the player's strategy, decision-making, etc. It is applied including Nike and Starbucks, but these companies have only marketing and applied advertisement (Iosup \& Epema, 2014). Literature review also reveals that the use of games elements in education has been applied across all levels of education from primary schools ( $\mathrm{Su}$ and Cheng (2015) to secondary education (Giannakos, 2013), and higher education (Dib \&Adamo-Villani, 2014).

\section{Similar applications}

The game-based education after the year 2010 is projected a big step forward compared to previous years. Deterding et al., have studied and formed a scientific definition for gamification. In their article they emphasize the use of the elements of the game is not a game environment (Deterding et al., 2011).

Prior to the development, research has done after a similar-themed web applications, or similar content search. We have examined several running applications on the market such as Farmerama, FarmVille and also an older PC software, SimFarm. We concluded that a similar application do not exist neither on the market nor in education, although the Simfarm in the early 90s has been used for championships as economical management application with a supplied moderator CD. Then we began the design and development of a commercial application.

\section{Material and method}

For the game development we used programming languages and technologies enabling the application to be widely available on the Internet as a Web page. We used the following programming languages: PHP on server side, client-side JavaScript, HTML and CSS are responsible for displaying, and MySQL as database. This application as a web page is available to anyone and do not need to download by the user and therefore it is completely platform independent (Lengyel et al. 2016). 
The website has developed in object oriented PHP. PHP is one of the most widely used and fastest server-side programming languages. The PHP itself is a scripting language used in one of the oldest and thus are well-known, regularly developed and maintained software languages. Since we wanted to develop it relatively quickly we used a framework, the Zend Framework 2 (ZF). The ZF is an objectoriented PHP based open source framework, which is related to the Model View Controller (MVC) logic (Pope, 2009). The essence of MVC that it separates data sets from user content (Figure 1.) and associate with the so-called controller when each page is loaded (Burbeck, 1987).

Thanks to the modular design of ZF the parts of the game can be separate and reused as well, which greatly facilitates the further development.

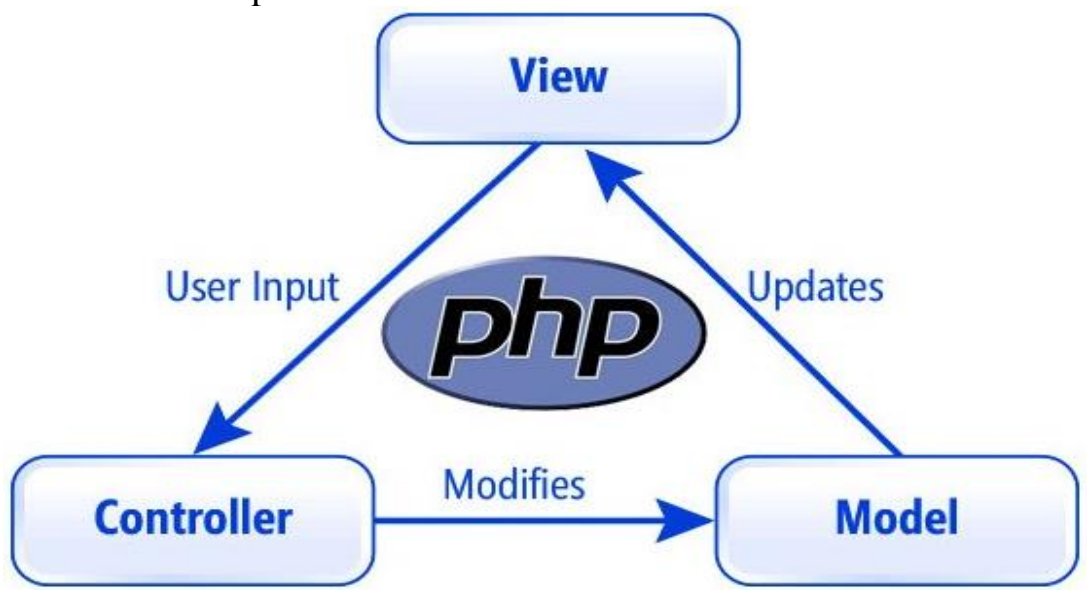

Figure 1. The logic of MVC planning

Source: (BUX, 2015)

The website has been designed to avoid having the browser window refresh, thus the application is compare to a full-fledged program. In addition to it, thanks to this solution the load times are reduced to about a quarter. AJAX (Asynchronous Javascript and XML) was used for allowing communication between the browser and the server in the background.

\section{Results}

After nearly two years of work, the application was published on the internet in 2016 as Koronakirály (Crownking). The software has modules that help learning during playing, and a quiz module to increase knowledge. It is important to mention that we managed to create an application that can be used to increase professional knowledge, and also in academic competitions in a fun and entertaining way (Várallyai et al. 2016). The game is available for free. It is going to be available for public from autumn 2017. An optimized version is also going to be available for mobile phones. At the moment, the educational advancements for each profession and the regional weather modules are under development.

\section{Reality mapping with algorithms}

The game has a huge similarity to real life because it has factors which can directly affect the growth of the crops, such as weather, soil quality, soil maintain and the player's profession. Every factor has a multiplier value that will be used to multiply the average crop amount (the average national harvested crop amount for each crop), when a crop, forest, etc. is ready.

\section{Weather}

The weather was modeled using the data over the past hundred years in Debrecen, Hungary. We have created an average from hot and rainy days with the help of an algorithm, we have randomized the days and inserted them into a database. The different types of weather which can be found in the game are: regular, sunny and rainy. Unfortunately, the game's weather does not contain temperature and humidity, due to the lack of data. A weather change occurs in every thirty minutes. The weather 
changing algorithm works by first selecting the last weather from the database, and then inserting it into a table of days that have already passed. After every change the algorithm checks if the previous four weathers are the same. If they are the same, it creates a weather disaster that will be assigned to every active (crop growing) soil. These disasters modify the harvested crops yield at various percentages. These percentages are selected randomly from 25, 50, 75 and 100 to simulate the impact of drought or flooding. Currently, the weather changes occur nationally, but the next version will account for regional changes.

\section{Soil Maintenance}

After the planting there are many services available in the game for the soil. The use of services like soil works and crop protection increases the yield of harvested crops which can be exchanged for money or gold. To be able to use the services the player should own the machines that have been allocated to the services and also should have enough experience points. If the player does not satisfy any of the previously mentioned factors, the service will not be available. In addition, each service is only available for a period. For example, the soil works is only available for the first $20 \%$ of the total growing time for that crop, while spraying is only available until the first $60 \%$ of the growing time. This feature was created to simulate a real-life scenario in when the player forgets to carry out a task at the right time. Yet, this is not a limitation factor for the yield of crops, as a standard yield of crops will grow without the use of these extra services. These services are only available to enhance the yield of crops. Each service is only usable once per growing cycle. The algorithm for this use similar method as the disaster, by adding positive multipliers with a small difference and allocating them to the soil.

\section{Professions}

Since there several profession available, every profession has its own multiplier, which is checked at every harvest or collection by the harvesting algorithm. If the algorithm detects that the player planted a crop which is not related to the player's specialty, it reduce the profession's multiplier as negative value. However, if the player grows a crop that is related to their profession, it will multiply positively. This method guarantees the difference between the professions and simulates the professional knowledge of the player. When comparing a beekeeper and a gardener, the gardener is more likely to grow more fruits on actual land in comparison to the beekeeper, since the gardener has more knowledge about fruits than the beekeeper. Similarly, the beekeeper is produce more honey than the gardener. This is reflective of how things work in real life hence because the algorithm sets this difference with the aid of multipliers.

\section{Golden crown, growing areas}

The word "Crown" can be found in the title of the game. Hungarians use "crown" as a measure of the quality of the soil. This soil measure system has also been integrated into the game. There are 18 different types of land which can be found in the game ranging from forests to greenhouses. Each type has multipliers allocated to them, which are negative if the quality of soil is bad and positive if the quality of soil is good. For example, in the county of Hajdú-Bihar a high golden crowned soil has a better growth rate, in comparison to soils in Heves county with inferior quality. There is another factor that modifies the crop amount of a soil. The planting method allocates a multiplier to every single newly planted crop, which is active until the crop is not collected/harvested by the player. This multiplier can be any value between -0.03 to 0.03 . This is to ensure that a certain piece of soil does not always have the same crop yield, like in real life. With this algorithm, we are simulating the different areas.

\section{Ingredient processing}

From the harvested crops, many different products can be made. Every product can be created from multiple types of crops, as well as from other products. These products are defined in the database, to be able to create infinite types, with different compositions. As a result in every version update, more products can be added to the game. These processes are categorized for the ease of use. A process can 
be selected when the player has the required ingredient, enough currency and experience points. When the process has ended, the final product can be collected and if the requirements are met the process can be applied again. The final product can be sold with a higher value than the total value of the ingredients.

\section{Beekeeping}

Beekeeping is a novel feature to this game as it does not exist in any other farming games. The player can choose from two types of bees; simple bees and gold bees. Since there are different species of bees which vary in strength and productivity, the gold bees generate twice the amount of honey as a simple bees. The bees are plant-specific and only produce honey when placed onto specific plants. After an hour, the bees and the honey can be collected. However, the plant where the bees are placed on cannot be harvested while the bees are producing honey. If the bees are retrieved before the process ends, very little or zero honey will be produced. The bees start collecting the honey only from the second quarter of the growing time, and also simulate the plant's blossoming.

\section{A brief presentation about the application}

In this section, we briefly review the farm simulation application, which got the name Koronakirály (Crownking). First of all, we write a few words about the name choice. We have chosen a name that is connected to Hungary and related to agriculture and also easy to remember. Then we chose the domain name Koronakirály (Crownking), because the word „aranykorona” (GoldenCrown) from the Hungarian soil rating was appropriate for us. In the application, there are three difficulty levels and five chosen profession which are the following: forestry, plant production, horticulture, beekeeping and lifestock breeding.

The modules designed to related and also close to each other as shown in Figure 2. We start with number one on the top left corner. First, we can see yellow threads on the wheat bags, which show the user's experience points, and the stars contain the levels that limit the number of sections (county). Under this part we can find the money module, which contains cash and gold. Number two indicates the weather module. The weather algorithm contains the last three weather states, and the actual weather condition in the green frame. Number three is a module series: combination the number of bees and machines, and finally the game statistics. First, we highlight, that only the beekeeper owns 700 bees. For other professions 200 bees are available. The machine module processes, the tractor, treatment and the machinery equipments needed for outstanding planting and harvest. The next part is the statistics, where the users can look up their stock, money, experience points (XP) and also the crop prices in daily and monthly periods. So this part assists in user-evaluating by decisions of users, like they had good or bad sales. At the end of the line, we can find the exit icon and the system time. Number four shows the services which are able to make products using crops. At the bottom of the figure, we can see the stock of crops and products. Here are those plants, which have already been produced and also we can sell and buy herein later. The sixth part is the mission module. It contains the profession specific missions, where the user may have to offer crops in exchange for various rewards. Last but not least, the seventh module is a map of the different parts, counties and regions of Hungary. The map shows the different growing areas: foil tents, orchards, forests and soils where the user can do yield. It is important that in this section, the landscape design was considered both in a graphical sense and keeping an eye on the cultivation techniques, so we can grow plants specific to the given land, thus providing a more realistic feeling. 


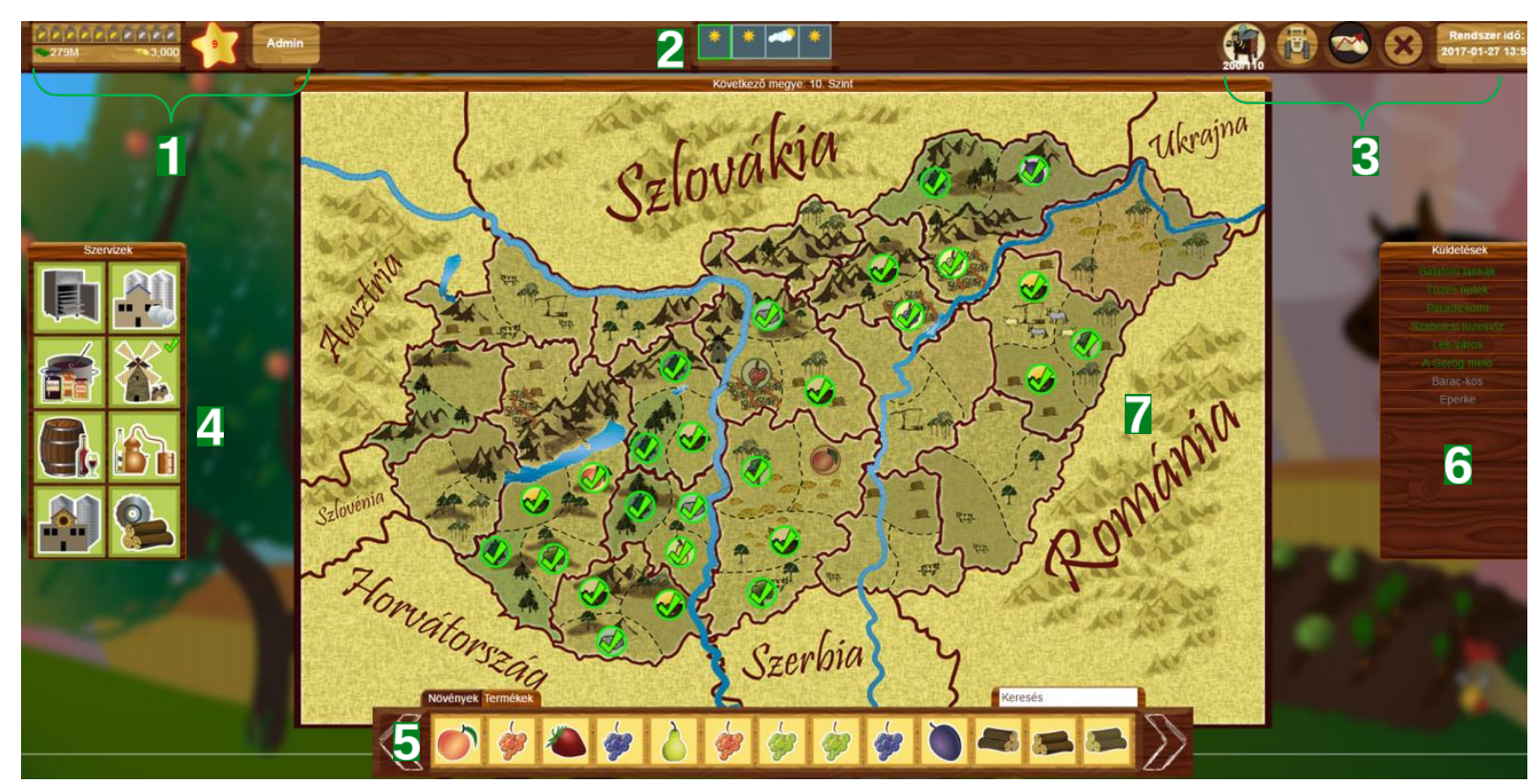

Figure 2. The "Koronakirály" application user interface

1, Experience, levels and money 2, Weather 3, Bees, machines and statistics 4, Services 5, Stock of crops and products 6, Missions 7, Map

Source: Own figure, 2017

\section{Database schema}

The modular design itself means that the components (modules) operate independently of each other and are thus able to stand alone with the help of the common control unit. Each plugin is globally available for all modules. Below is a brief description of the modules (Figure 3).

\section{Application - Applikáció}

This is a main module that is first uploaded when someone opens a web page. In this module there is a main screen and a cron. Cron is a background task manager that runs programs at certain intervals. This is a module to map a map around them after logging in the modules. When someone opens www.koronakiraly.hu and is not logged in, the module will disable the login / registration screen. If you are already signed in, you will be redirected to the Map module.

Bee -Méh

This is responsible for bees because in this module you can buy and sell bees. When you click on a map to collect bees, the module performs the calculations and modifies the number of bees.

\section{Bottombar -Alsó csík}

This is a module in a frame for Plant and Product Modules. The module itself does not include any impressions and JavaScript. Use activities for Plant / Product Warehouse Management.

\section{Chart -Statisztika}

The module is responsible for the appearance of in-game statistics. In this module, you can view stock, price, empirical point, money, and level changes. The module's Nick Downie Chart.js function is built.

\section{Plant -Növény}

The module controls crop production. This module can be used to plant or harvest / harvest plants to be produced / produced. Each plant and the bottom strip fog should appear. The module uses a CropStock to handle the stock, while the Money and XP plugins are being harvested.

Tamás Kovács, László Várallyai Krisztián Nagy, Róbert Szilágyi: Development of Farm simulation application, an example for gamification in higher education 


\section{Game -Játék}

This module is passive compared to the active parts known so far. Since there is not a single multiplayer game in parallel, so this gadget is just so used to sign up everyone in the first gameplay. If more gameplay is created then this module will determine which player it belongs to.

\section{Machine -Gép}

This module is responsible for transmitting and receiving machines and for the Plant Module that this gadget is asked if the player has the right machine for the plant. The existence of machines for soil care belongs to this part.

\section{Map -Térkép}

This is one of the most important modules as it sees the user after entering. The module chunks and then categorizes (prepares counties) Map and categories of Hungary will put the already available areas at predefined points. When a player's level of experience and money is sufficient, the module offers the player to select a new county. The module connects the Plant and Bee modules with the map of Hungary. The green bar around the map that shows you whether there is any production. Rostyslav Bryzgunov was created using the jquery-circle-progress plugin.

\section{Products -Termékek}

The module contains products made from plants. It is possible to determine infinite quantities and varieties of plants, so that several basic products can come up in the future. These products can be produced in the Service module. The module uses a ProductStock plugin to manage the stock and the Money plugin at the sale and purchase transaction.

\section{Quest - Küldetés}

You can pick up missions and execute quests in the "Quests" window on the right side of the game. The mission is usually the production of a sufficient amount of a plant or product. Upon completion, a module removes a product / plant from a stock store and adds the reward money / gold to the existing one. To do this, you use a CropStock / ProductStock, Money and XP plugins. The mission has a deadline that will block users for a week.

\section{Question - Kérdések}

Each player gets an opportunity once a day to answer a question related to your profession. Questions are a good answer and there are several options to choose from. If a player responds well to a question, he or she will receive a money or a gold reward. The Question module uses the money and $\mathrm{XP}$ modules to credit the reward.

\section{Service - Szervíz}

On the left side of the screen are the service categories that are categorized. Each category can be one or more service to create products. This production is made from one or more plants and / or products within a given time if the player has enough money / gold and his experience point. For warehouse management, CropStock and ProductStock plugins use the module as well as money and experience points for Money and XP plugins.

\section{Study -Tanulás}

The module is not yet fully completed so it is not yet available on the game (BuiltV3). The plugin will be responsible for learning. Each player will have the opportunity to learn more professions. To do this they must reach at least sixth level. You can then hire a job as a subject, which you should take a short 20-25 exam a week later. If an exam succeeds, then a profession can be considered as learned 


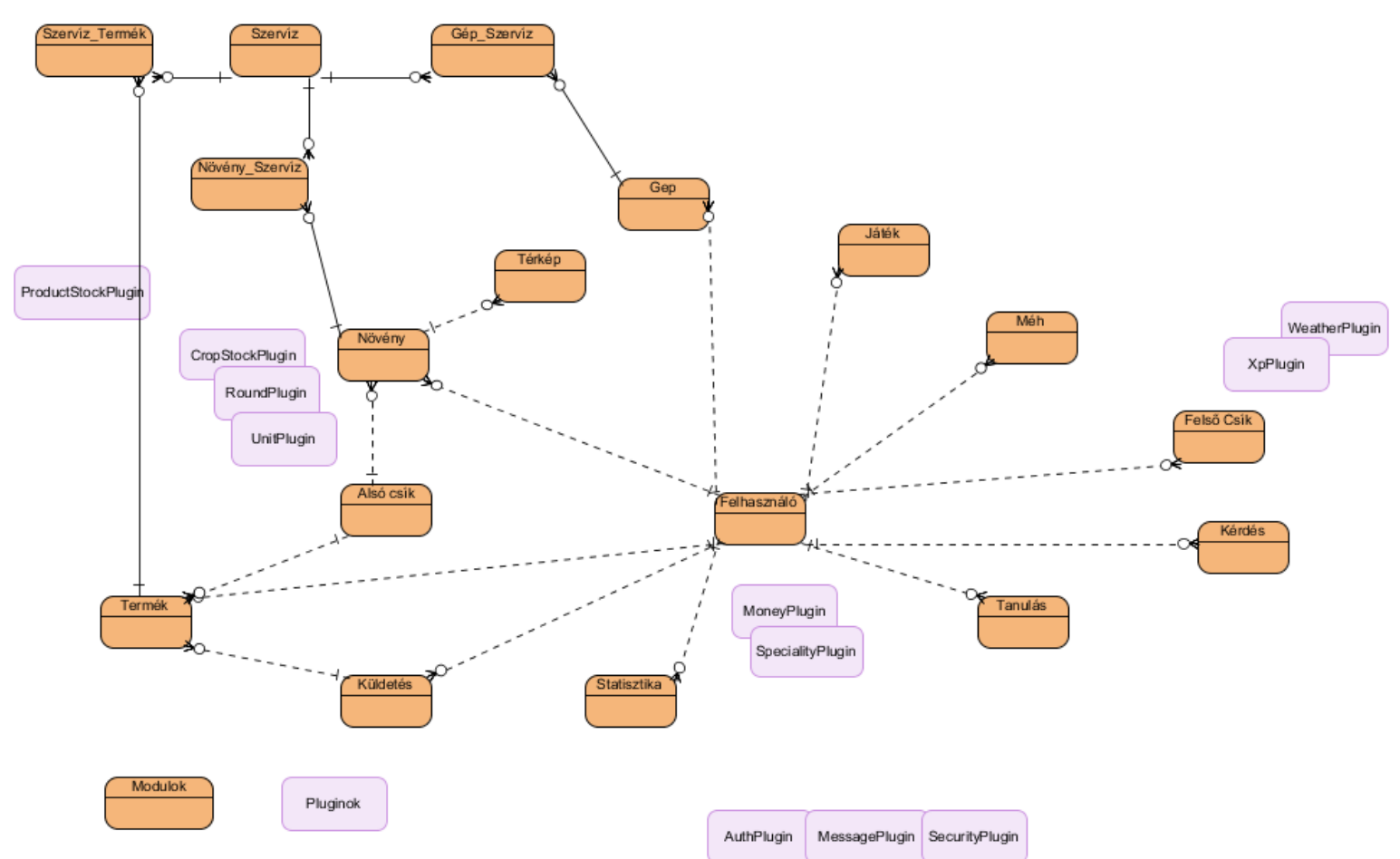

Figure 3. Database schema, plugins and modules

Source: Own figure, 2017

\section{Conclusions of tests and possibilities}

In this section we compare our application to other farm simulators, and agri-management applications. We mention the importance of user feedback and effectiveness briefly, as we discuss possibilities for further development of our application. During testing, the application was developed on the basis of a total 30 user reviews. This solution took place in two rounds. The first testing goal was correcting modules, and produce user-friendly interface. The second purpose of testing was the elimination of minor errors. The total testing time is spent about $\sim 20,000$ hours. The practical test location will be Gammar Schools and High Schools in Debrecen for the third testing.

\section{Comparison}

Table 1 shows a comparison of the application we encountered, based on defined criterias. Considering the nature of the application, it can be said that with the exception of SimFarm, these applications are mostly arcade games. Our application has a more realistic look, feel and elements. As for the programming language, we should know that Flash script language stands out from the other languages as it provides a more realistic motion in games. The "Koronakirály" application was written in PHP language so that is why it is a dynamic webpage. The gameplay is linear but also contains parts like missions. In terms of commerce, simple production and sales are present in other applications. As opposed to this, our solution contains prices and possibilities of processing that vary based on trade and offers. For this reason, the entire agro-business is carried out. The weather algorithm was included in SimFarm and "Koronakirály" applications during the reviewed period of time, however, only our solution was based on the actual trends. 
Table 1. Comparison with similar applications

\begin{tabular}{|c|c|c|c|c|}
\hline & SimFarm & Farmerama & FarmVille & Koronakirály \\
\hline Application nature & Arcade /Realistic & Arcade & Arcade & Realistic/Arcade \\
\hline Program language & Flash & Flash & Flash & PHP/JavaScript \\
\hline Gameplay & Linear & Linear & Linear & Linear \\
\hline Commerce & Yield and sales & Yield and sales & Yield and sales & Agribusiness \\
\hline Prices & Constant & Constant & Constant & Variable \\
\hline Weather & Variable & $\varnothing$ & $\varnothing$ & Variable \\
\hline
\end{tabular}

Source: Own table, 2017

\section{User feedback}

We carried out two tests in recent years at the campus of University of Debrecen - Faculty of Economics and Business involving nearly 30 participants and a half year in total gaming time. During testing, the modules got more functionalities and were further developed based on user feedbacks as well as announcements made on the basic bug fixes. The next test will take place in vocational schools this spring. We can say that we have received positive feedback on the overall functionality, but many look forward the mobile version of the application.

\section{Opportunities}

Our conclusions determine the future duties as the application is under constant development. After testing and receiving the results we have drawn the conclusions. The gamification is not generally known in many countries and neither in our region so that is the reason why it is not used frequently in education. The "Koronakirály" application may help this situation, mostly in higher education in Hungary. However, there has been little discussion on the topic in the Hungarian scientific literature so we had to use international trends. In our opinion, this application can easily become a tool for competitions in higher education and vocational schools alike, because it includes some modules that can help students in learning. Nevertheless, the quiz module can reward the players, and it can equip them with higher level of professional skills. The possibility of further education is another realistic element that can help to reduce the trade gap, so it can give a more complete picture of the domestic relations for the users. In addition, a useable professional literature and knowledge can be acquired with this application.

\section{Suggested modules:}

- Credit module completion

- Investigation player strategies

- Data mining

- Mobile optimization

- Commodities expansion

- Study competition adaptation

Our suggested modules are based on user feedbacks, because they showed a clear direction for further development. That is why we are going to develop the economy line of the application, which contains complex modules like: total credit system, commodities and it may become a simple economy simulation software in the future. 


\section{References}

Bognár M. (2009): Internet egyszerúen. Panemkiadó, Budapest, p.388 (ISBN: 978963-545507-2)

Botos Sz., Herdon M., Várallyai L. (2015): Readiness for Future Internet Services in Rural Areas, Procedia Economics and Finance 19: pp. 383-390. https://doi.org/10.1016/S2212-5671(15)00039-8

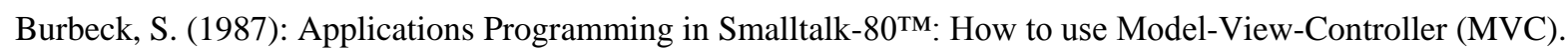
pp. 1-3, tanulmány

Bux, I. (2015): Best Codes MVC for PHP Developers.

Clark, D. B., Nelson, B. C., Chang, H.-Y., Martinez-Garza, M., Slack, K., \& D’Angelo, C. M. (2011). Exploring Newtonian mechanics in a conceptually-integrated digital game: Comparison of learning and affective outcomes for students in Taiwan and the United States. Computers \& Education, 57(3), 2178-2195.

https://doi.org/10.1016/j.compedu.2011.05.007

Deterding, S., Sicart M. Nacke L. (2011): Gamification: Using Game Design Elements in Non-Gaming Contexts Proceedings of the SIGCHI conference on Human factors in computing systems. ACM New York, NY, USA, Vancouver, Canada, pp.1-2

Dib, H., \&Adamo-Villani, N. (2014). Serious Sustainability Challenge Game to Promote Teaching and Learning of Building Sustainability. Journal of Computing in Civil Engineering, 28, A4014007.

https://doi.org/10.1061/(ASCE)CP.1943-5487.0000357

Farmerama https://www.farmerama.com/

Farmville https://www.zynga.com/games/farmville

Giannakos, M. N. (2013). Enjoy and learn with educational games: Examining factors affecting learning performance. Computers \& Education, 68, 429-439. https://doi.org/10.1016/j.compedu.2013.06.005

Hanus, M. D., \& Fox, J. (2015). Assessing the effects of gamification in the classroom: A longitudinal study on intrinsic motivation, social comparison, satisfaction, effort, and academic performance. Computers \& Education, 80, 152-161. https://doi.org/10.1016/j.compedu.2014.08.019

http://www.prowebmobile.com/best-codes-mvc-for-php-developers

Iosup, A. - Epema, D. (2014): An experience report on using gamification in technical higher education. SIGCSE14 Proceedings of the 45th ACM technical symposium on Computer science education, pp.27-30, (ISBN 978-1-4503-2605-6)

Lengyel P., Füzesi I., Péntek Á., Herdon M. (2016): Human resource development using e-learning for Hungarian agricultural experts, Journal of Agricultural Informatics 7:(1) pp. 94-102.

https://doi.org/10.17700/jai.2016.7.1.262

Martí-Parreño J., Seguí-Mas D., Seguí-Mas E. (2016): Teachers’ Attitude towards and Actual Use of Gamification, Procedia - Social and Behavioral Sciences, Volume 228, pp. 682-688 https://doi.org/10.1016/j.sbspro.2016.07.104

McGonigal, J. (2011). Reality is broken: Why games make us better and how they can change the world. New York: The Penguin Press.

Pope, K. (2009): Zend Framework 1.8 Web Application Development. Packt Publishing Ltd., Birmingham, pp. 2-4, (ISBN 978-1-8471-9422-0)

Ráthonyi G., Ráthonyi-Odor K., Várallyai L., Botos Sz. (2016): Influence of social media on holiday travel planning, Journal of Ecoagroturism 12 (1) pp. 57-62.

SimFarm http://www.mobygames.com/game/sim-farmSu, C.-H., \& Cheng, C.-H. (2015). A mobile gamification learning system for improving the learning motivation and achievements. Journal of Computer Assisted Learning, 31(3), 268-286.

Várallyai L., Herdon M., Burriel C., Pancsira J., Lengyel P., BotosSz. (2016): Collaborative working environment and knowledge databank for agroforestry training and education, International Journal of Sustainable Agricultural Management and Informatics 2: (2/3/4) pp. 222-242. h https://doi.org/10.1504/IJSAMI.2016.10002895

Z. Karvalics L. (2007): Információs társadalom - mi az? Egy kifejezés jelentése, története és fogalom környezete. Gondolat Kiadó, Budapest, pp. 29-46, (ISBN 978-963-693-061-5) 